\title{
Sin ensañamiento pero injustificadamente
}

Keywords: derecho; legislación; jurisprudencia; animal

El año que se nos ha ido, ha dejado a sus espaldas algunas buenas noticias en tema de protección animal. Parece como si el Derecho empezara a despertarse de un largo letargo en relación a los animales y quisiera, lentamente, desplegar ese manto de buena voluntad, del que hablaba Jeremy Bentham, para empezar a ocuparse con compasión de todo lo que respira en la faz de la tierra ("Why should the law refuse its protection to any sensitive being? The time will come when humanity will extend its mantle over everything which breathes....)[1] . Por ello, aunque recapitule en unos pocos puntos, todo lo que hemos avanzado en estos meses que han quedado atrás, me dispongo a formular algunas ideas que puedan servir para impulsar una mejora aún más decidida y solvente del Derecho, que nos coloque en la primera línea ("Front Row”) de la defensa de los animales, de todos sin excepción.

En el apartado de buenas noticias, figura el título de mi "paper” de este mes, que quiere deliberadamente ser una paradoja. No busco confundir, sino resaltar lo que el Código Penal en su artículo 337 ha logrado: un hacer sin hacer, con ánimo de sosegar.

El 23 de diciembre 2010, con cierto desganado alborozo, nos despertamos con los titulares de algunos periódicos [2] , que recogían los comentarios de asociaciones animalistas y de particulares, que se mostraban muy satisfechos con la (supuesta) mayor protección de los animales en el reformado Código Penal [3]. Se acentuaba en dichos comentarios que, se suprime en la nueva redacción del artículo 337 CP, el agravante de ensañamiento [4] para apreciar el delito de maltrato animal [5], lo que es cierto, y por lo que, sin duda cabe felicitarse. Pero también es cierto -y por ello hablo de paradoja- que ha permanecido la palabra injustificadamente, como calificativo del maltrato animal. En otras palabras: que cabe maltratar a un animal y no ser castigado por ello, si el castigo que se le aplica está “justificado”. No puedo por menos que levantar las cejas con asombro, mientras me pregunto: ¿Cuándo, cómo y por qué puede justificarse el maltrato a un animal que le cause la muerte o lesiones graves, que menoscaben gravemente su salud?.

Es cierto que la permanencia en la anterior redacción del artículo 337 CP del ensañamiento, producía fuertes discrepancias en los tribunales, pues dejaba sin castigo conductas en las que el maltrato del animal se producía, pero, al no poder apreciarse "ensañamiento”, se absolvía el autor de hechos, en sí mismos, execrables [6]. Sin embargo, la reforma es alicorta e insuficiente pues mantiene en la aplicación de la condena un margen de impunidad para el maltratador. Si en lugar de animales, pensamos en maltrato a un ser humano, un niño, un anciano, una mujer ¿cabe sostener que el maltrato puede estar justificado y que los tribunales pueden aplicar la eximente de “justificación de maltrato” al aplicar una sanción?.

Por lo demás, la reforma ha mantenido las mismas sanciones que la redacción del 2003 (“...tres meses a un año de prisión e inhabilitación especial de uno a tres años para el ejercicio de profesión, oficio o comercio que tenga relación con los animales”), lo que, es claro, no tiene ningún efecto disuasorio en el eventual maltratador. Se ha perdido una magnífica ocasión de ejemplarizar, con un castigo proporcional a la crueldad del maltrato animal, el deseo de la sociedad española, cada vez más sensible a la condición de los animales y a su bienestar. 
reiterar, con la perspectiva (aún corta) que el tiempo nos brinda, que la percepción de gran parte de la población española ha cambiado. A día de hoy, se puede seguir discrepando de la prohibición de las corridas de toros, pero la discusión ha saltado de los pequeños círculos animalistas a la prensa internacional y a la opinión abierta de los ciudadanos, que se atreven a abordar con franqueza un tema que ha estado muchos años sometido a silencio y a tópicos repetidos.

Otra gran noticia es que en la UAB empezamos este mes el primer Postgrado Universitario en "Animales, Derecho y Sociedad”, con el convencimiento de que la formación profesional en este ámbito, va a suponer una mejora en el estatuto y la situación de los animales en España. Ser pioneros supone un esfuerzo extra, una buena dosis de optimismo y una madurez que el equipo que abordamos esta aventura apasionante, desde luego, tenemos.

Queda, no obstante, mucho por hacer. Entre otras cosas:

1.La UE que ha marcado las pautas de los Estados Miembros en los últimos años (2006-2010) en tema de bienestar animal, sobre todo en lo relativo a los animales de producción (transporte, sacrificio, salud, battery cages, etc) [8], pretende fijar su atención en los próximos años (2011-2015) en una mejora de la legislación comunitaria relativa a los animales de compañía [9], sobre los que las diferencias entre los diferentes Estados son notorias. De hecho, carecemos de una norma europea común que fije los estándares de cuidado y protección y que determine unas estrategias eficaces de prevención, especialmente en tema de abandono. Esa es una línea de actuación en la que todos tenemos que trabajar. En España, donde la tasa de abandonos es altísima [10], tenemos que emplearnos a fondo, para desarraigar lo que es una verdadera lacra social.

2. Formación y profesionalización. Es en sí mismo todo un Programa, como también la UE ha señalado ("Education in Animal Protection") y una apuesta de futuro. Los animales necesitan nuestro cariño, nuestra empatía, nuestra protección, bien cierto es. Y necesitan también de nuestros conocimientos, de que nos preocupemos de lograr una base social sólida formada en la compasión y la empatía y ese objetivo se logrará empezando por la Escuela, continúando en la Universidad y prosiguiendo en los Programas de Formación Continuada, Postgrados, Másters y Doctorados. En todos los Programas Educativos debería de incluirse una asignatura de Protección y Legislación Animal y en la Universidad, en las Facultades de Derecho debería de incluirse como asignatura ordinaria el Derecho Animal. En la $\mathrm{UAB}$, la imparto yo misma desde hace ya 5 cursos académicos y es una asignatura del nuevo Plan de Estudios de Bolonia en nuestra Facultad. El pensamiento crítico, el conocimiento del estatuto jurídico de los animales, es el instrumento más eficaz para lograr mejoras en nuestros textos legales y en la aplicación del Derecho por los Tribunales. Nada más eficaz que la enseñanza en las Escuelas, en los Institutos, en todos los Centros Educativos para sensibilizar y mejorar el trato con los animales y para contribuir a su protección.

3. Un objetivo jurídico, pero también social y político. Romper barreras tejidas desde antaño. La defensa de los animales no es ya cosa de unos pocos. Puede convertirse -y así lo espero- en una prioridad social y política. Probablemente los resultados tardarán en alcanzarse, pero las nuevas generaciones -y ahí sí puedo dar datos fehacientes- reaccionan con interés y urgencia ante lo que hasta ahora había sido una actitud reservada a pequeños grupos de activistas: los animales importan y cada vez a más ciudadanos.

Este año 2011 nos depara muchas incógnitas. Trabajar en primera línea (Front Row) es asumir riesgos conscientes y apasionantes: “working for animals!”, como me repitió en su felicitación de las últimas fiestas un ilustre colega americano (que forma parte del Consejo asesor de esta Web Center), que lleva muchos años -y mucha ilusión y trabajo- en alcanzar también estos objetivos que he ido señalando, a modo de ejemplo. 
[1] BENTHAM, J., An Introduction to the Principles of Morals and Legislation, 1789. Latest edition: Adamant Media Corporation, 2005.

[2] Vid. p.e.: Link externo

[3] BOE 23 de Junio 2010, Ley Orgánica de 22 de junio de 2010 Descargar.

[4] Se entiende por “ensañamiento” una circunstancia que agrava la responsabilidad del agente, que causa en la víctima un padecimiento innecesario, o no-ordinario, bien sea por el dolor que se provoca a la víctima o por la prolongación de su agonía, buscando provocar deliberadamente un sufrimiento que excede la mera ejecución del delito.

[5] CP. Art. 337:“Los que maltrataren con ensañamiento e injustificadamente a animales domésticos causándoles la muerte o provocándoles lesiones que produzcan un grave menoscabo físico serán castigados con la pena de prisión de tres meses a un año e inhabilitación especial de uno a tres años para el ejercicio de profesión, oficio o comercio que tenga relación con los animales.”

CP. Art. 337 reformado: "El que por cualquier medio o procedimiento maltrate injustificadamente a un animal doméstico o amansado, causándole la muerte o lesiones que menoscaben gravemente su salud, será castigado con la pena de tres meses a un año de prisión e inhabilitación especial de uno a tres años para el ejercicio de profesión, oficio o comercio que tenga relación con los animales”.

[6] AP La Coruña, Secc. 1, 10.6.2009 (arrojar por la ventana al gato); AP Valencia, Secc.3, 26.2.2009 (matar a un gato golpeándolo con una pala escavadora).

[7]GIMÉNEZ-CANDELA, T., Toros y toreros

[8] Vid., esp. los informes del Consejo de Europa Link externo

[9] Vid. noticia en la web Center Descargar

[10] La Fundación Affinity publica cada año una estadística reveladora, que vale la pena consultar Link externo. Sobre ello, vid. esp.

GIMÉNEZ-CANDELA, T., $\underline{\text { Abandonados }}$ 